\title{
A escola da prisáo como espaço de dupla inclusáo: no contexto e para além das grades
}

\author{
Elenice Maria Cammarosano Onofre*
}

\section{Resumo}

O objetivo deste artigo é apresentar algumas reflexóes sobre o papel da escola para jovens e adultos em situaçáo de privaçáo de liberdade, buscando evidenciar que a prisão, embora seja uma organização que constrói uma experiência ancorada no exercício autoritário do poder, tem na escola um espaço de aprendizagens, que se constituem em fatores contributivos de (re)socialização e de reinserção social do homem aprisionado. A metodologia de pesquisa utilizada, um estudo de caso, tem como seu objeto de estudo a escola de um presídio masculino, de segurança máxima, do interior do estado de São Paulo/Brasil. Os procedimentos metodológicos foram análise documental, conversas informais e entrevistas semiestruturadas, com amostra de alunos e professores da escola. Os resultados obtidos evidenciam que, apesar de tolhido em sua individualidade, despido do pertencimento à sociedade, duplamente excluído - pelo analfabetismo e pelo estigma por ter passado pela "universidade do crime" -, o processo de escolarizaçáo do homem aprisionado afigura-se como possibilidade de construção da identidade perdida e do resgate da cidadania, que a privação da liberdade confere ao homem que teve sua trajetória de vida marcada pela passagem na sociedade dos cativos. Palavras-chave: escola da prisão, educação de adultos presos, inclusão escolar, processos educativos na prisão.

The prison school as a place for two-fold inclusion: behind bars and beyond

\begin{abstract}
The aim of this article is to present some reflections on the role of the school for young people and adults deprived of their freedom. It is an effort to show that even if prison is an organization that constructs experience based on authoritarian power its school provides learning experiences which contribute to the re-socialization and social re-rooting of the prisoner. The research methodology, a case study, uses the school in a men's maximum security prison, in upstate São Paulo, Brazil, as its object of study. The methodological procedures

* Professora do Departamento de Teorias e Práticas Pedagógicas e do Programa de Pós-Graduação em Educação da Universidade Federal de São Carlos (UFSCar). Área: Processos de Ensino e de Aprendizagem. Linha de Pesquisa: Práticas Sociais e Processos Educativos. E-mail: linocam@uol.com.br.
\end{abstract}


were desk research, informal conversations and semi-structured interviews with a sample of students and teachers from the school. The results show that, although the exercise of their individuality is restricted, and they are deprived of belonging to society, and doubly excluded - through illiteracy and the stigma of having gone through the 'university of crime' - the prisoner's schooling is seen as a means of building a lost identity and reclaiming the citizenship that the privation of freedom imposes on people whose lives have been marked by time spent in prison.

Keywords: prison school, adult education for prisoners, school inclusion, educational

Este estudo foi elaborado com o intuito de aprofundar discussóes existentes em relação às possibilidades e limites da educação escolar no sistema prisional. Tais discussões têm enfatizado as dificuldades em desenvolver, efetivamente, um programa de educação, se este estiver ligado ao esquema de funcionamento da prisão, cujo caráter é essencialmente disciplinar.

Nesse espaço, a reabilitação, por constituir-se em um processo regido por normas e regras com primazia centrada na aceitação da situação, acaba por promover a despersonalização e anulação dos sujeitos. A educação, por seu lado, almeja a formação de pessoas, a ampliação de sua leitura de mundo, o despertar da criatividade, a participação na construção do conhecimento e a superação de sua condição atual.

Seria pretensioso, e mesmo ingênuo, propor a elaboração de respostas definitivas para um problema polêmico como é o das contradiçóes existentes nas organizaçôes penitenciárias, em relação à reabilitação e educação tarefas a elas destinadas.

No entanto, os processos de adaptação dos indivíduos ao sistema social do cárcere não são plenos. Encerram contradiçôes, uma vez que os aprisionados encontram e constroem formas de resistência, e a educação não permanece neutra nesse processo. Os estudos sobre educaçáo de adultos em situação de privação de liberdade têm mostrado a possibilidade de se construir a escola nas prisóes enquanto espaço diferenciado das prerrogativas carcerárias. (PENNA, 2003; ONOFRE, 2002; SANTOS, 2002; LEME, 2002; PORTUGUÊS, 2001; SILVA, 2001).

Para a construção dessa escola, há que se considerar que existe descompasso entre o que ela deve e o que pode fazer no interior das prisóes. A proposta educacional traçada para essas escolas, ao explicitar as concepçóes sobre o homem, sobre o mundo e sobre a educação e a produção de conhecimento, enfatiza que a educação, para ser válida, deve levar em conta 
tanto a vocação ontológica do homem (vocação de ser sujeito) quanto as condiçôes nas quais vive (contexto). Toda ação educativa tem como princípio fundamental desenvolver no indivíduo competências e habilidades, para que tenha condiçóes de transformar o mundo em que está inserido, não se tornando um instrumento de ajuste à sociedade.

É preciso, pois, que, ao tomar consciência de sua realidade, o homem procure refletir sobre ela, comprometendo-se em transformá-la. O que se precisa ter presente é se a atividade educativa está sendo desenvolvida para a libertação dos homens - a sua humanização - ou para a sua domesticação. Sobressai, então, a importância da clareza sobre as diferentes formas de ação no campo educacional, a fim de tornar possível a opção ou escolha pelos caminhos que se pretende tomar.

Como afirma Freire (1983), não é apenas necessário saber que é impossível haver neutralidade da educação, mas é preciso distinguir esses diferentes caminhos. A escola é uma instituição que existe num contexto histórico de uma determinada sociedade. Para que seja compreendida, é necessário que se entenda como o poder se constitui na sociedade e a serviço de quem está atuando.

A escola é um texto escrito por várias mãos e sua leitura pressupóe o entendimento de suas conexóes com a sociedade e de seu próprio interior. Resgatar a identidade da escola, sua intencionalidade, seus compromissos é tarefa dos educadores, em quaisquer espaços educativos.

O seu papel de promover situaçôes em que as interações e a intersubjetividade estejam presentes, enfatizado nos depoimentos dos alunos e professores que compartilharam do estudo apresentado neste texto, nos permite evidenciar a ideia de que os homens fazem a história a partir de uma dada circunstância concreta e de uma estrutura que já existe. A sala de aula de qualquer espaço educativo é portadora de várias culturas, várias cidadanias, várias entidades, e a escola trabalha com esse jogo complexo de filiaçóes e pertences. Apesar dos limites de caráter ideológico, social, político e cultural, o professor tem presente que o elemento fundamental da eficácia de seu papel reside no processo de resgate da liberdade e a escola é uma das instituiçóes que melhor cumpre a tarefa de oferecer possibilidades que libertam e unem, ao mesmo tempo. Se o aprisionado vive em função desse resgate, não há que se medir esforços para o repensar da escola e de outras práticas educativas que ocorrem no interior das prisóes. 
O caminho percorrido: metodologia de trabalho e sujeitos da pesquisa

Dadas as peculiaridades da temática estudada - a educação escolar de adultos em situação de privação de liberdade -, utilizou-se o estudo de caso como metodologia de trabalho, entendido como uma "investigação sistemática de uma instância específica” (NISBETT e WATT, 1978, p. 5). A característica mais distinta de tal metodologia é a ênfase na singularidade e no particular, pois isso implica que o objeto de estudo seja examinado como único. O estudo de caso enfatiza a importância de contextualizar as informaçôes e situaçôes retratadas, sendo necessário que o pesquisador esteja atento aos elementos e dimensóes que vão emergindo dos estudos e aos aspectos inicialmente não previstos.

Nesse sentido, durante o período de inserção no espaço, para coleta dos dados, em contato frequente com a realidade pesquisada - a escola de uma unidade prisional de segurança máxima, do interior do estado de São Paulo -, o foco de atenção foi se aprofundando a cada momento. Além disso, embora se buscasse um contato mais próximo com os professores, com a equipe de educação e com os alunos, por meio das entrevistas e conversas informais, foi possível conviver também com a diretoria geral, diretoria de reabilitação, advogados, assistentes sociais, psicólogos, guardas e funcionários.

Desse convívio, ocorreram reflexóes que, organizadas em diários de campo, permitiram cruzar informaçóes, confirmar hipóteses e descobrir novos dados da realidade investigada.

A esse conhecimento experiencial, foram associadas informaçóes e reflexóes, frutos de experiências pessoais em outros espaços escolares. As comparaçóes foram evidenciando semelhanças e diferenças entre a escola da prisão e as escolas "da rua", e embora houvesse inicialmente a ideia de que seriam encontradas muitas diferenças, foram constatadas inúmeras semelhanças referentes ao trabalho educativo, à valorizaçáo do professor pelas instâncias superiores, às relaçóes de poder.

Por outro lado, as falas advindas de diferentes informantes dentro da penitenciária, sobre o objeto de estudo, e que não pareciam conflitantes à primeira vista, aos poucos revelaram, embora os discursos fossem semelhantes, importantes diferenças nas entrelinhas. Foi possível perceber, de um lado, o discurso "da casa" e, de outro, o discurso dos professores. 
Para entender a sociedade dos cativos, como esclarece Sykes (1999), é preciso estar sintonizado com a contradição e permanecer neutro, pois as realidades da detenção são multifacetadas. Há que se ter presente que o significado de qualquer situação é sempre um complexo de pontos de vista, muitas vezes conflitantes, e que é na divergência que se começam a ver os aspectos significativos da estrutura social da prisão.

Buscando uma postura de neutralidade e com a atenção voltada às contradiçôes do espaço pesquisado, estabeleceu-se o recorte de análise nos agentes que constituem o espaço da sala de aula. A preocupação central do estudo foi compreender como os alunos e professores veem a escola na penitenciária, buscando uma representação singular da realidade, sem desvinculá-la do contexto em que está inserida, até porque este determina as açôes que se desenvolvem no interior da escola.

Tendo em vista o contexto em que se realizou a pesquisa, torna-se relevante considerar que a chegada, como pesquisadora, no espaço prisional, constituiu-se em um verdadeiro "ritual de passagem": estive sujeita a olhares de interrogação e de intimidação. Ali estava presente uma realidade em que se entrecruzam o "visto" e o "lido", o visível e o enunciável e descortinava-se um espaço de pesquisa em que seria preciso vivenciar momentos de contradição entre o dito e o feito, de regras rígidas e verticalizadas, mas que permitiriam desenvolver a habilidade de escuta e de observação apurada às entrelinhas.

Como mencionado anteriormente, o recorte dos sujeitos incidiu nos alunos e professores da escola de uma penitenciária do interior do estado de São Paulo.

Em relação aos alunos, usou-se, para seleção dos sujeitos de pesquisa, o processo de amostragem, sendo selecionados, inicialmente, 50 (cinquenta) sujeitos recém-incluídos, com idade de 20 a 30 anos e com famílias tidas como desestruturadas, por serem dados predominantes na população desta penitenciária.

Dos cinquenta sujeitos selecionados, apenas dezoito puderam ser entrevistados, embora as conversas tenham sido agendadas com antecedência. Os demais sujeitos não participaram das entrevistas, por estarem no hospital, terem sido excluídos (ido para outros presídios), estarem em trânsito (encaminhados a outras comarcas para responder processos), ou incomunicáveis no pavilhão E (local para onde são encaminhados quando cometem faltas graves). 
Isso demonstra a dificuldade encontrada na coleta de dados, mesmo porque o sujeito selecionado para entrevista pode, de um dia para o outro, não estar mais no presídio. Há uma mobilidade interna muito grande, o que dificulta o contato com os mesmos sujeitos selecionados durante um período de tempo muito longo.

Em relação aos professores, o grupo era composto de oito professores, universitários de duas Instituiçóes de ensino superior. Os universitários foram admitidos pela Fundação Professor Dr. Manoel Pedro Pimentel (Funap), tendo em vista o desligamento dos professores da rede pública de ensino da escola da penitenciária desde 1997, e foram efetivados, por meio de processo seletivo, pela própria Funap. Alguns professores cumpriam jornada de trabalho nos períodos da manhã e da tarde.

O perfil dos alunos foi traçado com dados retirados dos Boletins de Inclusão dos cinquenta sujeitos selecionados. Desses, dezoito foram entrevistados, com um roteiro de questóes que permitiu a coleta das informaçóes que se buscava, tendo em vista os objetivos propostos.

As entrevistas ocorreram em diversos momentos. O roteiro era organizado com base nas informaçóes anteriormente obtidas, que se enriqueciam e se aprofundavam à medida que a leitura da literatura apontava novas indagaçóes e reflexóes. Ao mesmo tempo, foram realizadas anotaçóes em diários de campo, nas quais houve preocupação de enfatizar observaçóes do cotidiano prisional e fatos que ocorreram em momentos anteriores e posteriores às conversas com os alunos, o que permitiu organizar material de consulta para análise dos dados.

O perfil dos professores foi traçado com informaçōes da Diretoria de Educação da penitenciária. Com eles, foram realizadas entrevistas semiestruturadas, buscando informaçóes que permitissem analisar o ideário dos professores, o modo como avaliam o papel da escola dentro do contexto do presídio e o seu papel nesse espaço.

Da mesma forma que se procedeu com os alunos, houve preocupação em respeitar os professores colaboradores em relação ao horário estipulado, ao seu universo de valores, cumprindo os acordos com suas conveniências e garantindo o sigilo das informaçóes obtidas.

Com os professores, foi usado o gravador em todas as entrevistas, visto terem concordado com tal procedimento, o que náo aconteceu nas conversas com os alunos. 
Os focos de análise emergiram dos dados coletados nos Boletins de Inclusão, informações da Diretoria de Educação, observações do cotidiano, conversas informais e entrevistas com alunos e professores da escola da penitenciária. Conforme se afirmou anteriormente, não foram utilizadas categorias a priori, prontas e acabadas. Partiu-se do pressuposto de buscar dados que emergem da realidade, realizando-se um trabalho de questionamento das raízes, limitaçôes e implicaçóes do material encontrado, pois o fato de ele ser retirado da realidade apreendida náo é garantia de autenticidade e de verdade.

\section{Significando a escola: a percepçáo de alunos e professores}

Dos relatos dos alunos e professores foram selecionados trechos dos discursos nos quais se localizaram informaçóes de onde emergiram os focos de análise: significado da prisão para o aluno; significado da escola para o aluno; causas do abandono da escola da prisão; papel dos professores na escola da prisão; significado da figura do professor e da escola; a sala de aula como espaço de aprendizagem de conteúdos úteis para a vida; organização e funcionamento da escola na prisão: dificuldades encontradas.

Atendendo ao objetivo desse texto, buscou-se enfatizar os aspectos voltados ao papel da escola [leitura e da escrita] enquanto fator contributivo de (re)socialização e de (re)inserção do homem aprisionado - soltar as amarras, quebrar as armadilhas existentes entre as grades, por meio da educação escolar, é um desafio aos educadores que lutam pelo respeito aos direitos humanos, independentemente do espaço em que as pessoas estejam inseridas.

$\mathrm{O}$ isolamento na prisão produz no indivíduo a sensação de perdas pessoais, como explicita Goffman (1974), quando observa que o encarcerado passa por um processo de descaracterização de sua identidade adquirida anteriormente nas relaçóes com a família, amigos e instituiçóes religiosas, educacionais, profissionais.

Nesse sentido, buscar a escola para ampliar conhecimentos é uma maneira de resistir ao processo de perdas a que a prisão submete o indivíduo, uma vez é a região mais sombria do aparelho de justiça que organiza silenciosamente um campo de subjetividade em que o castigo poderá funcionar em plena luz como terapêutica (FOUCAULT, 1987).

Existe entre os aprisionados um sentimento de tempo perdido, destruído ou tirado de suas vidas, e que pode configurar-se como motivo 
que os leva à escola. A volta à sala de aula oferece a muitos deles a possibilidade de poder sair da cela, "distrair a mente" e ocupar seu tempo com coisas úteis, como se pode comprovar no estudo realizado.

Quando os alunos referem-se à escola como espaço onde ocupam a mente com coisas boas e preenchem o tempo ocioso, pode-se atentar para a falta de atividades em que vivem. Ora, é preciso ter presente que os criminosos são colocados na prisão, não para punição, mas como punição. Não precisam, no dizer de Sykes (1999), ser agredidos física ou mentalmente, além da dor envolvida no próprio confinamento. Eles não estão ali para serem punidos, pois o muro já é a segregação e o castigo. A escola, portanto, além de ser uma ocupaçáo, proporciona-lhes a possibilidade de se relacionarem com o mundo externo. Ali, eles têm contato com práticas e opinióes externas às do mundo prisional, que é carregado de símbolos relacionados ao mundo do crime.

A resposta mais frequente dos entrevistados, em relação ao significado da escola, está relacionada à oportunidade de aprendizado da leitura e escrita para os não alfabetizados, que são os mais frequentes, os que mais valorizam a escola e os que apresentam a menor porcentagem de evasão.

Ler e escrever na prisão é fundamental, pois não ter essas qualidades implica dependência do companheiro. É com esses conhecimentos que os detentos podem escrever e ler cartas, bilhetes e acompanhar o desenrolar dos seus processos criminais.

No dizer deles, é preciso ficar atento, porque a justiça não tem preocupação com eles e o cumprimento da pena sempre vai além do determinado no momento da condenação. Nesse sentido, de posse da leitura e da escrita, buscam lutar para ter seus direitos respeitados.

$\mathrm{Na}$ prisão, ler e escrever significa, portanto, ter mais liberdade, autonomia e privacidade, até porque quem não sabe pede, e quem pede deve. $\mathrm{Na}$ prisão até favor é dívida, e dívida é risco de vida.

Em relação ao significado da escola para o aluno, é preciso, também, que sejam destacadas, de acordo com os depoimentos, as expectativas que demonstram em relação ao acesso aos conhecimentos e melhorias das condiçóes de vida, quando em liberdade. Do ponto de vista da aprendizagem, os objetivos da escola são mais concretos e reais, pois uns querem aprender a ler, escrever e calcular, outros buscam aperfeiçoar, aprofundar e ampliar seus conhecimentos. Essa visão não é muito diferente da análise feita por Mello (1987, p. 78), quando afirma que "[...] é ensinando a ler, escrever, calcular, 
falar, e transmitindo conhecimentos básicos do mundo físico e social, que a educação escolar poderá ser útil às camadas populares".

Para a autora, os alunos presos, assim como as camadas populares, veem a educação como "formas de melhorar de vida, pela possibilidade que nela distinguem de obterem melhor emprego e de participarem da cultura letrada” (MELLO, 1987, p. 77).

Essa expectativa é ainda maior nos homens encarcerados, pois, além de pobres, são presos. A educação não pode ser considerada "toda poderosa”, mas é preciso ter o cuidado de não cultivar o pessimismo, achando que a educação nada pode.

Como afirma Santos (2002, p. 105), "faz parte do imaginário dos detentos a expectativa de ter acesso aos conhecimentos acumulados, via escola, e isso não sofre variação se essa instituição está dentro ou fora de uma prisão".

Pode concluir-se, então, que a escola no presídio guarda especificidades que a diferenciam de outros espaços, e que a sociedade dos cativos mantém expectativas em relação à instituição escolar quanto à aquisição de conhecimentos e preparo para o convívio social.

Pensar a educação escolar no presídio significa, nesse sentido, refletir sobre sua contribuição para a vida dos encarcerados e da sociedade em geral, por meio da aprendizagem participativa e da convivência baseada na valorização e desenvolvimento do outro e de si mesmo. Significa, ainda, pensar uma educação escolar capaz de fazer do preso um homem "informado e participante do mundo em que vive, adquirindo consciência crítica que favorece a capacidade de questionar e problematizar o mundo, condição necessária para a prática social transformadora” (MELLO, 1987, p. 90).

A leitura e a escrita aparecem como ferramentas úteis a realizar a formação desses homens que desejam ser "alguém". Sem dúvida, os que têm um grau de escolaridade mais elevado são mais respeitados e valorizados na prisão, seja por funcionários, seja por outros presos. A leitura e a escrita aumentam os conhecimentos, melhorando o relacionamento e criando novas maneiras de pensar, viver e comportar-se dentro e fora das grades.

Há que se ter presente que a perda da liberdade do aprisionado é dupla: primeiro, por confinamento na instituição, e segundo, por confinamento dentro da instituição. De acordo com Sykes (1999), à medida que os meses vão passando, as ligaçóes com as pessoas da comunidade livre vão enfraquecendo. Nesse sentido, é oportuno ressaltar a figura do professor e os vínculos que se estabelecem na escola. Mesmo sendo restrita a sua oportunidade de 
fazer escolhas, a sala de aula constitui-se em espaço que promove relativa autonomia, uma vez que na prisão está submetido a regras e comandos destinados a controlar o seu comportamento nos mínimos detalhes.

Concordo com Sykes (1999) quando afirma que, por algum tempo, os criminosos continuarão confinados, que os muros não serão demolidos, que é excessivamente otimista esperar que a prisão reabilite $100 \%$ dos reclusos, que a comunidade autoritária da prisão não necessita ser severamente repressiva, que não se pode ser indiferente e ignorar o sistema social da prisão ao se tentar mudar a sua natureza propondo uma política penal esclarecida.

Tal situação não impede, porém, de se buscarem formas de resgatar a dignidade, a liberdade psicológica e o bem-estar do aprisionado. A escola é um espaço que não precisa funcionar pelo avesso, podendo desempenhar um papel importante no resgate do status de cidadão, sendo o professor figura relevante no estabelecimento do vínculo de confiança que o aprisionado perdeu ao ser afastado da sociedade.

Para tanto, é preciso desmascarar alguns mitos sobre os riscos de se lidar com a população sentenciada, pois atrás desses mitos está o ceticismo e a postura elitista de administradores dessas organizaçóes, que, por se constituírem em donos do saber "especializado", desqualificam quaisquer propostas de mudanças.

O que se conhece da questão penitenciária no Brasil é um cenário de impasses e dilemas crônicos. Há uma realidade da qual não se pode fugir, mas é preciso buscar caminhos para o repensar da melhoria das instituições penais.

Os programas educativos estabelecidos para as prisóes devem estar inseridos em uma política pública de âmbito nacional, mas quando se pensa em formular esses programas, não pode ser esquecida uma referência básica - a relação futuro-presente-passado.

Para o aprisionado, essa relação é fundamental, em qualquer programa educativo que se lhe apresente. É o cotidiano que revela as bases sobre o que é possível, mas não deixa de trazer embutido o passado, enquanto memória e incorporação de vivências. Sua expectativa de futuro é algo que deve ser também considerado. A escola pode oferecer condiçóes para que ele possa conviver, no presente, com diferentes circunstâncias, sabendo a hora de "mostrar-se" ou "esconder-se", de falar ou de calar, de proteger-se para sobreviver. $\mathrm{O}$ aprisionado traz, por outro lado, enquanto memória, vivências por vezes negativas, de situaçóes pelas quais passou antes e durante sua carreira delinquencial. Em suas expectativas de futuro estão o desejo de 
começar uma nova vida, na qual possa trabalhar, voltar a estudar e construir uma família. Embora os estudos sobre a reincidência criminal apontem que suas expectativas acabam, na maioria das vezes, frustradas pelos rótulos, pelo despreparo em assumir atividades profissionais, por distorçóes de visão de mundo que fatalmente adquirem na "sociedade dos cativos", é necessário que sejam prosseguidos estudos em busca da (re)construção de projetos educativos que visem a melhoria das escolas das unidades prisionais.

$\mathrm{O}$ que assistimos neste momento é uma efervescência de ações de diferentes segmentos da sociedade, de órgãos das esferas federal e estadual, de entidades envolvidas na implementação das Diretrizes Nacionais para a oferta de educação para jovens e adultos em situação de privação de liberdade nos estabelecimentos penais, aprovadas em 2010, num esforço de elaborar políticas públicas que atendam às demandas por elas estabelecidas e de criar mecanismos que possibilitem avanços na qualidade da educação oferecida nas prisóes.

A contribuição deste texto é a de desvelar que também em um espaço repressivo, como é o caso das prisóes, a escola tem seu significado e sua essência mantidos, no estabelecimento de vínculos e de intersubjetividades. Se buscamos caminhos para a educação brasileira por acreditar na sua transformação, se buscamos uma sociedade mais justa em favor daqueles que historicamente tiveram negado o acesso aos direitos essenciais à vida humana e, entre eles, o direito à educaçáo, se apostamos no poder dos educadores porque em qualquer situação o possível existe e pode ser realizado, desde que tenhamos desejo de mudança, há que se incluir, nessa possibilidade, a educação dos excluídos que vivem no interior das unidades prisionais.

\section{Referências}

BRASIL. Parecer CNE/CEB n. 4/2010. Diretrizes Nacionais para a oferta de educação de jovens e adultos em situação de privação de liberdade nos estabelecimentos penais. Brasília, DF: MEC/CNE/SECAD, 2010.

FOUCAULT, M. Vigiar e punir: história da violência nas prisões. Petrópolis, RJ: Vozes, 1987.

FREIRE, P. Educação como prática da liberdade. Rio de Janeiro: Paz e Terra, 1983. 
LEME, J. A. G. A cela de aula: tirando a pena com letras. Uma reflexão sobre o sentido da educação nos presídios. 2002. Dissertação (Mestrado em Educação: História, Política, Sociedade) - Pontifícia Universidade Católica de São Paulo, São Paulo, 2002.

GOFFMAN, E. Manicômios, prisóes e conventos. São Paulo: Perspectiva, 1974. MELLO, G. N. Educação escolar: paixão, pensamento e prática. São Paulo: Cortez, 1987.

NISBETT, J.; WATT, J. Case study red guide 26: guides of Nottighan School of Education. 1978.

ONOFRE, E. M. C. Educação escolar na prisão. Para além das grades: a essência da escola e a possibilidade de resgate da identidade do homem aprisionado. 2002. Tese (Doutorado em Educação) - Unesp, Araraquara-SP, 2002.

PENNA, M. G. de O. O ofício de professor: ambigüidades do exercício da docência por monitores-presos. 2003. Dissertação (Mestrado em Educação: História, Política, Sociedade) - Pontifícia Universidade Católica de São Paulo, São Paulo, 2003.

PORTUGUÊS, M. R. Educação de adultos presos: possibilidades e contradições da inserção da educação escolar nos programas de reabilitação do sistema penal no Estado de São Paulo. 2001. Dissertação (Mestrado em Educação) - Faculdade de Educação, Universidade de São Paulo, São Paulo, 2001.

SANTOS, S. A educação escolar no sistema prisional sob a ótica de detentos. 2002. Dissertação (Mestrado em Educação: História, Política, Sociedade) Pontifícia Universidade Católica de São Paulo, São Paulo, 2002.

SILVA, R. da. A eficácia sócio-pedagógica da pena de privação da liberdade. 2001. Tese (Doutorado em Educação) - Faculdade de Educação, Universidade de São Paulo, São Paulo, 2001.

SYKES, G. M. The society of captives: a study of a maximum security prison. New Jersey: Princeton University Press, 1999. 